\title{
Customized self-expanding bare metal $Y$ stents in the treatment of malignant carinal stenosis: a retrospective analysis
}

\author{
Ting Wang, Jie Zhang, Xiao-Jian Qiu, Juan Wang, Ying-Hua Pei, Jin-Mu Niu \\ Department of Respiratory and Critical Care Medicine, Beijing Tiantan Hospital, Capital Medical University, Beijing, China \\ Contributions: (I) Conception and design: All authors; (II) Administrative support: J Zhang, XJ Qiu; (III) Provision of study materials or patients: T \\ Wang, J Wang, YH Pei, JM Niu; (IV) Collection and assembly of data: T Wang, J Wang, YH Pei, JM Niu; (V) Data analysis and interpretation: T \\ Wang, J Zhang; (VI) Manuscript writing: All authors; (VII) Final approval of manuscript: All authors. \\ Correspondence to: Jie Zhang. Department of Respiratory and Critical Care Medicine, Beijing Tiantan Hospital, Capital Medical University, 119 South \\ Fourth Ring West Road, Beijing 100070, China. Email: zhangj_tt@163.com.
}

\begin{abstract}
Background Self-expanding Y metal stent insertion is a safe and effective palliative method for malignant lesions involving the lower trachea, tracheal carina, and the main-stem bronchi. However, the length and degree of airway stenosis in different patients tend to vary, which leads to a call for a customized Y stent that could achieve a better treatment effect.

Methods: This retrospective analysis included patients who received customized self-expanding bare metallic Y stents for malignant carinal stenosis at Beijing Tiantan Hospital, Capital Medical University between January 2007 and June 2020. CT scans and initial bronchoscopy were performed to provide reliable data for stent selection and size customization. Data on technical success, clinical success, and follow-up were analyzed.

Results: A total of 36 patients (26 males and 10 females; median age, 61 years; age range, 30-83 years) were enrolled. Technical success was $97.2 \%$ (35/36), while clinical success was $97.2 \%(35 / 36)$. There was no procedure-related mortality. Out of 35 patients, 4 (11.4\%) had stent-associated complications that did not affect the procedure of stent insertion. Re-stenosis of the stent due to tumor progression was the main midand long-term stent-related complication ( $65 \%$ and $57.1 \%$, respectively), followed by stent fractures (5\% and $14.3 \%$, respectively).

Conclusions: The current study described the design and insertion of customized self-expanding bare metal Y-stents and demonstrated the feasibility of their use for maintaining tracheal and main-stem bronchus patency in malignant carinal stenosis. This approach could be used as a bridging method before commencing adjuvant therapy and final palliative therapy for the relief of symptoms.
\end{abstract}

Keywords: Central airway obstruction; self-expanding stent; tracheal stenosis; bronchoscopy

Submitted Nov 24, 2020. Accepted for publication Mar 01, 2021.

doi: 10.21037/apm-20-2332

View this article at: http://dx.doi.org/10.21037/apm-20-2332

\section{Introduction}

Malignant central airway obstruction is a life-threatening disease (1), in which malignant carinal stenosis is the most severe scenario. Resection surgery is usually contraindicated for a variety of reasons. For such cases, therapeutic interventional bronchoscopy is preferred as it is less invasive and suitable for critically ill patients.
Y-shaped silicon stents have been traditionally used to treat malignant carinal stenosis $(2,3)$. However, they have poor shape-adaptability, difficult placement, and secretion retention (4). Self-expanding Y metal stents are relatively easy to insert, and they lead to less secretion retention; but their length cannot be adjusted by clinicians like silicone $\mathrm{Y}$ stent, which leads to a call for a customized Y stent that could achieve a better treatment effect. 
Micro-Tech stents (Micro-Tech Corporation, Nanjing, China) are self-expanding metal (nickel titanium alloy) stents available in different shapes that are individually customizable. The current study described the design and use of customizable Micro-Tech self-expanding bare metal $\mathrm{Y}$ stents in malignant carinal stenosis, and the feasibility of using customized $\mathrm{Y}$ metal stents in the treatment of malignant carinal stenosis was evaluated.

We present the following article in accordance with the STROBE reporting checklist (available at http://dx.doi. org/10.21037/apm-20-2332).

\section{Methods}

The study was conducted in accordance with the Declaration of Helsinki (as revised in 2013). The study was approved by the Institutional Review Board of Beijing Tian Tan Hospital (approval ID: JS2013-007-02). All patients gave their written informed consent to undergo the stent insertion, and for their data to be used in this study.

\section{Patients}

This retrospective analysis included all patients with malignant carinal stenosis treated with a customized selfexpanding bare metallic Y stent at Beijing Tiantan Hospital, Capital Medical University between January 2007 and June 2020. Data including demographics, etiologies, stenosis locations, imaging findings, stent dimensions, technical success, and complications after stent placement were collected with the help of medical records and bronchoscopy records. Telephone calls were made to the patients and/or their relatives to get the most recent updates of the patient's condition. For patients who could not be reached by telephone, the last appointment date was considered as the censored date.

\section{Design of customized Y metal stents}

Multi-slice spiral computed tomography (MSCT) scans of the chest with $1.25 \mathrm{~mm}$ collimation, including coronal and sagittal reconstruction, and initial bronchoscopy were performed to provide reliable data for stent selection and size customization.

The $\mathrm{Y}$ stent contained a tracheal limb and two main bronchial limbs. Stent diameter of tracheal limb and bronchial limbs were determined by calculating mean diameters of healthy adjacent zones. The diameters of the adjacent healthy patent airway zone were measured in the axial plane as 2 orthogonal diameters. The "healthy adjacent zone" was defined as airway visible on CT images that were considered as normal morphology without any mass distortion of apparent reduction of normal diameter and without any fistula formation (5). The stent diameter (D) of the tracheal limb $[\mathrm{D}$ tracheal $=(\mathrm{XA}+\mathrm{YA}) / 2]$ and diameter of bronchial limbs $[\mathrm{D}$ bronchial $=(\mathrm{XB}+\mathrm{YB}) / 2]$ are shown in Figure $1 A, B$.

The length of the stenosis was also measured on coronal reconstructions, and $5-10 \mathrm{~mm}$ were added respectively to determine the length $(\mathrm{L})$ of the tracheal limb and bronchial limbs $\left[\mathrm{L}_{\text {tracheal limb }}=\mathrm{L}_{\text {stenosis of tracheal }}\left(\mathrm{L}_{\mathrm{T}}\right)+5-10 \mathrm{~mm}\right.$; $\mathrm{L}_{\text {bronchial limb }}=$ $\mathrm{L}_{\text {stenosis of bronchial }}\left(\mathrm{L}_{\mathrm{B}}\right)+5-10 \mathrm{~mm}$ ] (Figure 1C). The 5-10 mm addition at both ends was used to ensure that the stent will cover all the diseased parts. The angle of $Y$ stent $\left(A_{Y}\right)$ was determined by the angle between the long axes of the mainstem bronchus (Figure 1D), after which the stent parameters were marked on the drawing and sent to the manufacture (Micro-Tech Corporation, Nanjing, China). Finally, the customized $\mathrm{Y}$ stents were made and sent back to the hospital within 5 days.

\section{Stent placement}

Preoperative and pre-anesthetic evaluations were conducted by interventional pulmonologists and anesthetists, respectively. Before the stent was inserted, other interventional procedures, such as mechanical debulking, electrosurgery, and laser ablation, were also performed if interventional pulmonologists thought it was needed.

The customized self-expanding bare metal Y stent was loaded on a 27-F delivery catheter. It could be inserted orally or by rigid bronchoscopy. The early 12 cases performed until 2013 were orally inserted. With the patients under total intravenous anesthesia and remaining spontaneous respiration, both the guidewire and introducer sheath were inserted orally. The release process of the stent was the same as the bellow mentioned. After 2013, the placement of $\mathrm{Y}$ stents in our center was performed during a rigid bronchoscopy under general anesthesia with high-frequency jet ventilation in order to obtain a better tolerance and safety in patients. A rigid bronchoscope was inserted first, after which through the rigid bronchoscope, a 0.035 -inch guidewire (Boston Scientific Corporation, Marlborough, MA, USA) was inserted in the left or right main-stem bronchus via a flexible bronchoscope. The flexible bronchoscope was subsequently withdrawn, and the delivery 

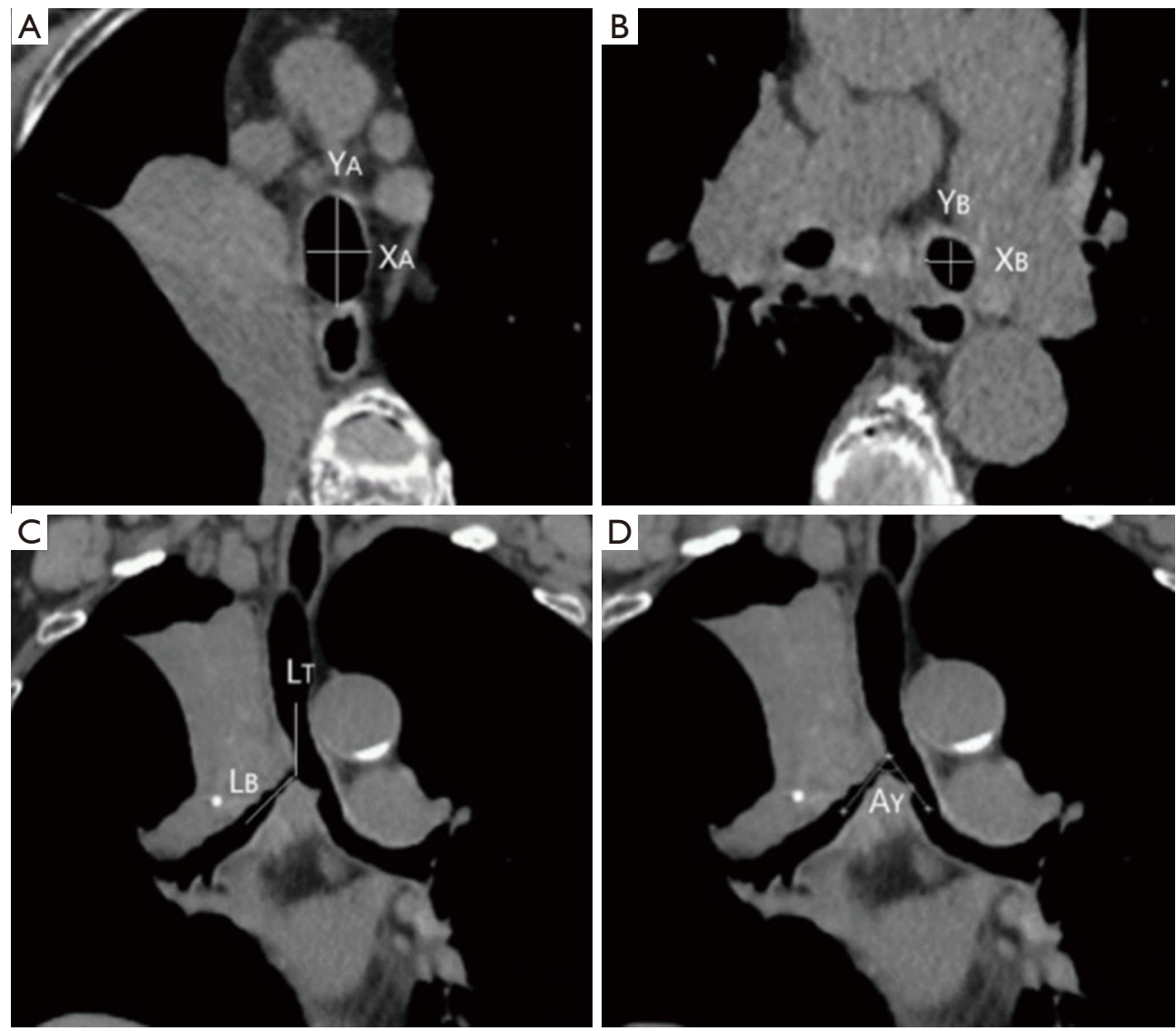

Figure 1 CT measurement of the tracheobronchial tree for determination of length, diameter, and angle of Y stent. (A) The stent diameter of tracheal limb $(\mathrm{D}$ tracheal $)=(\mathrm{XA}+\mathrm{YA}) / 2$. (B) The diameter of bronchial limbs $(\mathrm{D}$ bronchial $)=(\mathrm{XB}+\mathrm{YB}) / 2]$. $(\mathrm{C})$ The length of the tracheal limb $(\mathrm{L}$ tracheal limb) = L stenosis of tracheal $(\mathrm{LT})+5-10 \mathrm{~mm}$; the length of bronchial limbs $(\mathrm{L}$ bronchial limb) = L stenosis of bronchial (LB) $+5-10 \mathrm{~mm}$. (D) The angle of $\mathrm{Y}$ stent $(\mathrm{AY})=$ the angle between the long axes of the main-stem bronchus.

system was advanced into the carina with the corresponding bronchial limb of the stent passing over the guidewire. The bronchial limbs bound by threads were exposed after the initial retraction of the introducer sheath (Figure $2 A$ ). Under direct visualization through an ultra-thin flexible bronchoscope (LF-DP, OLYMPUS, Japan. Outer diameter: $3.1 \mathrm{~mm}$ ), the stent bronchial limbs were completely inserted into the relevant main-stem bronchus. The bronchial limbs were released by pulling the bound threads out of the delivery system by the ring-pull. The tracheal limb was released by further withdrawal of the introducer sheath, thus completing the stent placement (Figure 2B).

Figure 3 depicts a case that was evaluated preoperatively using the above method. The parameters of $Y$ stent were marked on the drawing (Figure $3 A$ ), and the drawing was sent to the manufacture to make a customized selfexpanding bare metal Y stent. Figure $3 B$ and Figure $3 C$ show the CT images obtained before stent insertion and after stenting.

\section{Assessment}

Technical success was defined as the exact placement of the stent, indicating successful deployment across the target lesion. Recorded respiratory support before and after the procedure was used as an indirect parameter of symptom improvement. Respiratory support was classified into 4 grades: breathing room air, low concentration oxygen therapy by cannula $\left(\mathrm{FiO}_{2} \leq 33 \%\right)$, high concentration oxygen therapy by mask $\left(\mathrm{FiO}_{2} \geq 35 \%\right)$, and invasive ventilation. Clinical success was defined as symptomatic improvement (at least 1 grade in the respiratory support) and improvement of the modified Medical Research Council (mMRC) dyspnea scale (at least 1 grade) after 

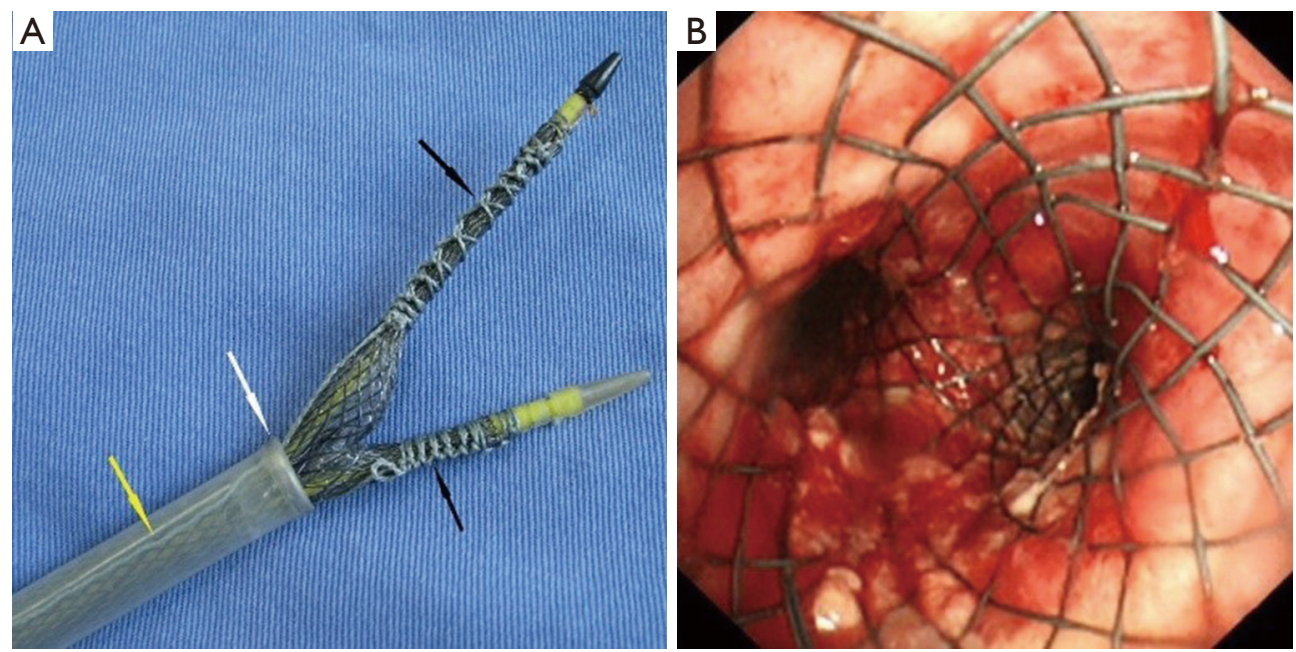

Figure 2 The customized self-expanding bare metal Y stent before and after released. (A) The bronchial limbs bound by threads (black arrow) were exposed after the initial retraction of the delivery catheter (white arrow); the tracheal limb (yellow arrow) was still loaded in delivery catheter. (B) The customized self-expanding bare metal Y stents were completely inserted.

stent placement. Complete pulmonary function testing was not available for all patients because most of the patients were unable to perform expiratory maneuvers due to the advanced stage of cancer.

\section{Procedure-related complications and follow-up}

The monitoring of procedure-related complications was carried out by evaluating any complications that were recorded in the patients' bronchoscopy records, and then evaluating whether these complications were related to the stent placement procedure.

Follow-up data were based on bronchoscopy records and imaging data. Short-term complications (1 week after the operation), mid-term complications (1-3 months after operation), and long-term complications (more than 3 months after operation) such as secretions retention, restenosis requiring further interventions, stent fracture, stent migration, and so on were recorded.

\section{Statistical analysis}

Descriptive statistics were used to tabulate the demographic characteristics of the study population. Quantitative data were expressed as mean \pm standard deviation $(\mathrm{SD})$. The chisquare test or Fisher's exact test was used to compare the categorical data between the two groups. For all tests, a $\mathrm{P}$ value $<0.05$ was considered statistically significant. Statistical analysis of the data was performed using SPSS version 22.0 (SPSS Inc., Chicago, IL, USA).

\section{Results}

Between January 2007 and June 2020, a total of 36 patients (26 males and 10 females; median age, 61 years; age range, $30-83$ years) with malignant carinal stenosis treated with a customized Micro-Tech self-expanding bare metal Y stent at Beijing Tian Tan Hospital, Capital Medical University were enrolled. The most common cause for malignant carinal stenosis was non-small cell lung cancer. Table 1 shows the baseline characteristics of enrolled patients.

Stent insertion was technically successful in 35 patients, resulting in the technical success of $97.2 \%(35 / 36)$. Insertion of the customized $\mathrm{Y}$ stent failed in one patient because the two bronchial limbs were early released before being completely inserted into the main-stem bronchus. The customized Y stent was removed immediately by an alligator biopsy forceps and a spare uncovered metallic cone-shaped stent was inserted instead. The patient was a 75 -year-old male who was diagnosed as squamous cell carcinoma of right lung and underwent surgical resection of the entire right lower lobe and right middle lobe. Tumor recurrence was found in the lower part of trachea and carina. The proximal end $(18 \mathrm{~mm})$ of cone-shaped stent was positioned in the trachea while the distal end $(10 \mathrm{~mm})$ was positioned in the left main-stem bronchus. The meshes on 
A

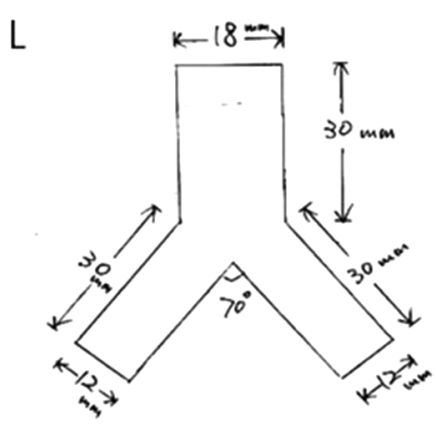

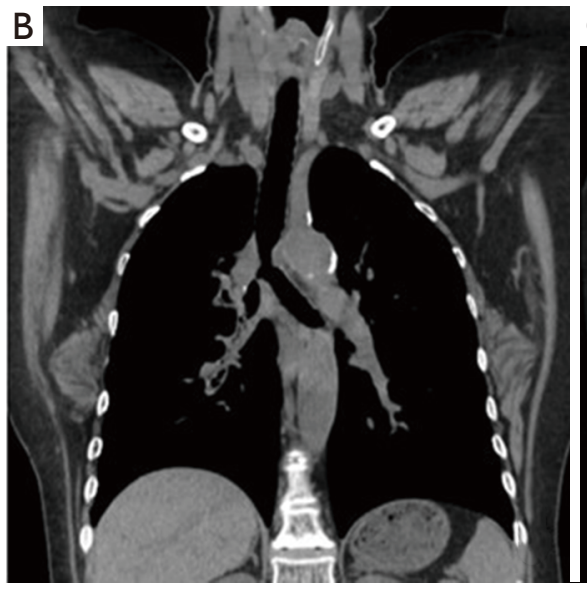

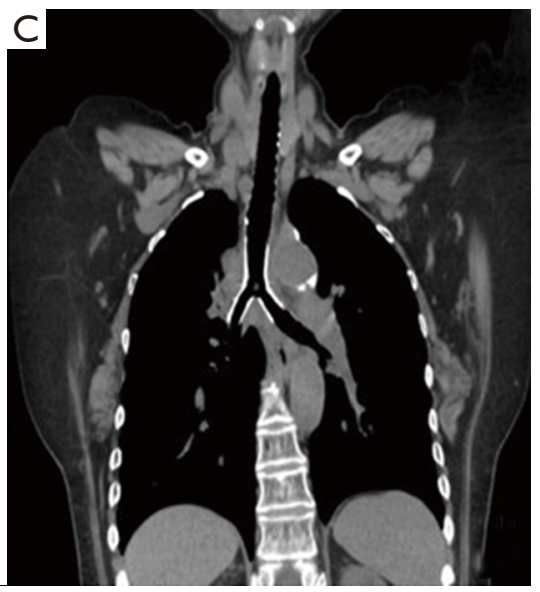

Figure 3 A 65-year-old woman with respiratory distress caused by tracheal-bronchial adenoid cystic carcinoma. (A) The parameters of customized self-expanding bare metal Y stent were marked on the drawing. CT images were obtained before (B) and after (C) stent insertion.

Table 1 Baseline characteristics of enrolled patients $(n=36)$

\begin{tabular}{lc}
\hline Variables & Value \\
\hline Age [range] & 61 [30-83] \\
Gender & $26(72.2)$ \\
Male & $10(27.8)$ \\
Female & \\
Disease & $4(11.1)$ \\
Lung adenocarcinoma & $17(47.2)$ \\
Lung squamous cell carcinoma & $1(2.8)$ \\
Lung large cell neuroendocrine carcinoma & $7(19.4)$ \\
Esophageal cancer & $5(13.9)$ \\
Tracheal-bronchial adenoid cystic carcinoma & $2(5.6)$ \\
Tracheal-bronchial mucoepidermoid carcinoma & \\
Stenosis location & \\
T, C, RB, LB & $30(83.3)$ \\
T, C, RB & $3(8.3)$ \\
T, C, LB & $2(5.6)$ \\
T, C & $1(2.8)$ \\
Follow-up, days & \\
Mean & 220 \\
\hline Range & \\
\hline
\end{tabular}

$\mathrm{T}$, trachea; C, carina; RB, right main-stem bronchus; LB, left main-stem bronchus. the cone-shaped stent near the opening of right main-stem bronchus was enlarged by laser cutting, which allowed the airflow and sputum could pass through.

Duration of follow-up ranged between 1 and 2,130 days, with a median of 57 days. Short-term follow-up data were acquired from 34 patients, mid-term follow-up data were acquired from 20 patients, and long-term follow-up data were acquired from 7 patients. Data on complications in remaining patients were incomplete because they did not attend further follow-up; they died of the fatal evolution of their malignant disease or changed to an unknown physician or were being treated in a different local hospital after the procedure. Figure 4 shows the flow diagram of this study.

\section{Clinical success}

Clinical success was achieved in all those 35 patients. The 35 customized $\mathrm{Y}$ stents used in this study had the following dimensions (Table 2). The clinical success rate was $97.2 \%$ $(35 / 36)$. The respiratory difficulty instantly improved after treatment and all of the patients experienced an improvement of at least 1 grade post-procedure. The 4 patients who received invasive ventilation before $\mathrm{Y}$ stent placement were extubated immediately post-procedure. The respiratory support grades of all patients were classified into Grade 1 (breathing room air) when they left anesthesia recovery room $(\mathrm{P}<0.0001$, Table 3). The average dyspnea index decreased from $3.14 \pm 0.73$ to $1.71 \pm 0.62$ before and 3 days post-procedure. 


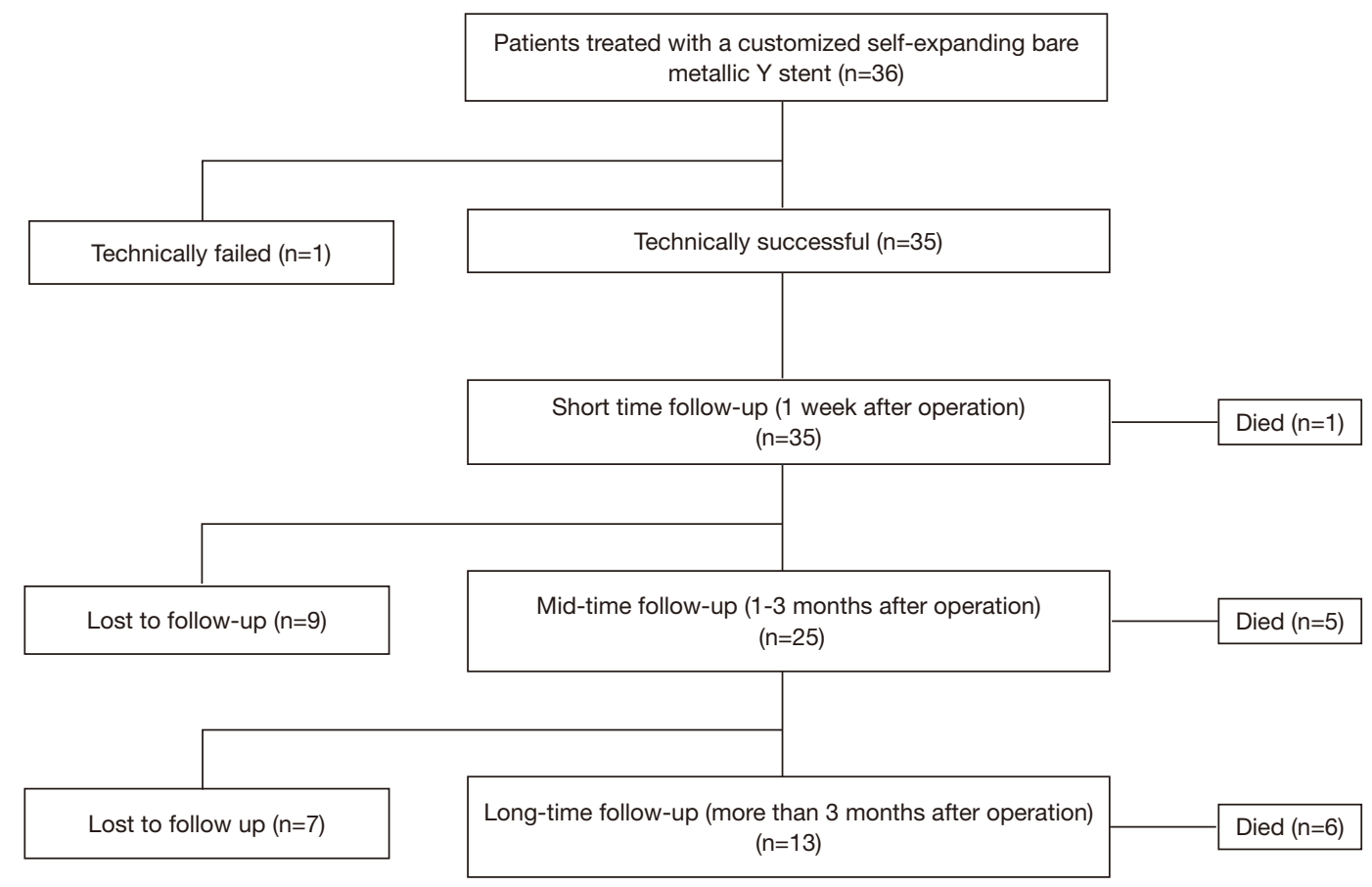

Figure 4 The flow diagram of this study.

Table 2 The dimensions of customizable $\mathrm{Y}$ stent

\begin{tabular}{lcccc}
\hline & \multicolumn{2}{c}{ Diameter $(\mathrm{mm})$} & \multicolumn{2}{c}{ Length $(\mathrm{mm})$} \\
\cline { 2 - 5 } Dimensions of $Y$ stent & Min & Max & 18 & Min \\
\hline Tracheal limb & 12 & 14 & 15 & 70 \\
Left bronchial limb & 8 & 14 & 10 & 45 \\
Right bronchial limb & 8 & 50 & 10 \\
\hline
\end{tabular}

\section{Complications}

There was no procedure-related mortality. Among 35 patients, 4 (11.4\%) had stent-associated complications recorded in bronchoscopy records, including bleeding that required the use of hemostatic drugs under bronchoscope ( 2 cases), and insufficient expansion of one side of the bronchial limb, which need a balloon dilation (2 cases). These complications did not influence the procedure of stent insertion. All patients were advised to use nebulization of acetylcysteine $(0.3 \mathrm{~g}, 3 \mathrm{~mL})$ and normal saline at least twice daily after $Y$-stent insertion. Excess secretion retention was not seen in any of the patients.

Short-term follow-up data were acquired from 35 patients. One patient died at the 1st postoperative day due to type I respiratory failure caused by acute pulmonary embolism, 1 patient had pneumothorax at the 1st postoperative day due to severe cough and was cured after closed drainage, and 1 patient had facial edema at the 1st postoperative day because the Y stent squeezed tumor, which led to superior vena cava obstruction syndrome.

Mid-term follow-up data were acquired from 25 patients, in which 5 patients died of the fatal evolution of their malignant disease. Out of 20 patients survived, 13 patients $(65 \%)$ had re-stenosis of the stent due to tumor growth and needed further interventions, 3 patients (15\%) had stent fractures, and 1 patient (5\%) had tracheoesophageal fistula because of the progression of esophageal cancer.

Long-term follow-up data were acquired from 13 patients, in which 6 patients died of the fatal evolution of their malignant disease. The longest follow-up time was 2,130 days. Out of 
Table 3 Respiratory support before and after Y stent placement in 35 patients

\begin{tabular}{lcc}
\hline \multirow{2}{*}{ Respiratory support grade } & \multicolumn{2}{c}{ Stent insertion } \\
\cline { 2 - 3 } & Before & After $^{\star}$ \\
\hline 0 (breathing room air) & 0 & 35 \\
1 (low concentration oxygen therapy & 25 & 0 \\
by cannula, $\left.\mathrm{FiO}_{2} \leq 35 \%\right)$ & & \\
2 (high concentration oxygen therapy & 6 & 0 \\
by mask, $\mathrm{FiO}_{2} \geq 40 \%$ ) & & 0 \\
3 (invasive ventilation) & 4 & 0 \\
\hline
\end{tabular}

$\mathrm{P}<0.0001$, Chi-Square test. *, the timepoint when patients left anesthesia recovery room.

7 survived patients, 4 (57.1\%) had re-stenosis of the stent due to tumor growth that needed further interventions, and 1 patient $(14.3 \%)$ had stent fractures. No migrations or stent-associated mortalities were observed.

\section{Discussion}

The first Y-stent was a silastic stent developed in 1972 by Neville and colleagues (6). Throughout the following years, airway stents were further advanced, and nowadays, different Y-stents that differ in material, rigidity, and insertion technique are available. One of the most commonly used Y-stents is the Dumon Y-stent that is useful and is welltolerated in the management of malignant carina stenosis. However, it's not without disadvantages. The placement of silicone Dumon stent requires preliminary dilation of the stenosis, which usually increases the operating time. Other disadvantages include poor shape-adaptability, granulation tissue formation, secretion retention, and migration (4).

Self-expandable metallic Y-stent offers a precise adaptation to irregular airways and is easier to place $(7,8)$. Compared with silicone Y-stent, the self-expandable metallic Y-stent has easier adoptability under topical anesthesia, even when the patient's performance status is not good enough for general anesthesia. Moreover, due to their thin walls, metallic stents have a larger internal luminal diameter than silicone stents, which allow for better clearance of secretions. In previous studies, the selfexpandable metallic Y-stents used were not customizable, and that came in very limited sizes $(9,10)$. Since doctors cannot adjust the length of self-expandable metallic Y-stent as silicone stents, some patients may receive self-expandable metallic Y-stents with the unsuitable size. An undersized stent can lead to stent migration; an oversized stent can lead to excessive radial force being placed on the airway mucosa, which in turn may lead to overgrowth of granulation tissue, and less commonly, erosion or perforation (1).

Micro-Tech stents (Micro-Tech Co., Ltd., Nanjing, China) are self-expanding metal stents that are available in different sizes and are individually customizable. These materials (nickel titanium alloy) possess a so-called memory effect, meaning that the stent returns to its originally designed shape and size after having been deployed (11). In this study, all patients got a customized self-expanding metal Y-stent inserted. The diameter and length of the tracheal limb varied from 12 to $18 \mathrm{~mm}$ and from 30 to $70 \mathrm{~mm}$, respectively, and the diameter and length of the two bronchial limbs varied from 8 to 14 and 10 to $50 \mathrm{~mm}$, respectively. These customized Y-stents offer a more precise adaptation to irregular stenosis airways, thus achieving better treatment effects and avoiding related complications. In this study, no migrations were observed. One patient had tracheoesophageal fistula at the mid-time follow up; however, this was not stent-related and was caused by the progression of esophageal cancer.

Re-stenosis of the stent due to tumor progression was the main mid- and long-term stent-related complication in this study. However, for most patients, further interventions could be performed to relieve the re-stenosis, and when possible, adjuvant tumor-specific therapy could be given. The defining prognostic factor for the further survival of the patients with malignant airway stenosis is the course of the underlying malignancy (9). Stent fractures occasionally occurred during the mid/long term follow-up. In the previous study, the average survival time of malignant airway stenosis patients was not very long (12), therefore, stent fracture could be occasionally tolerated except in case of severe complications or if the patency of the airway could not be maintained. In fact, in this study, none of the patients needed to remove the stent and/or re-implant a new stent.

MSCT scans, including coronal and sagittal reconstruction, provides invaluable information in the initial evaluation of a patient (13). First of all, it could provide measurements for the length, diameter, and location of the involved airway segment, proximal and distal diameter of the healthy adjacent zones, the angles between the two main bronchi, thus providing detailed information for the design of customized Y-stent. Secondly, for cases in which the initial bronchoscopy evaluation fails to visualize the airways beyond the site of obstruction, multi-slice CT serves as an important adjunct study by providing detailed anatomic 
information of the distal airways. Finally, multi-slice CT also provides important complementary information regarding the relationship of the stenosis airways to other adjacent structures that are not visible at bronchoscopy, so as to anticipate any possible complication related to the stents. In this study, one patient had facial edema after operation, which was caused by $\mathrm{Y}$ stent squeezing the tumor and leading to superior vena cava obstruction syndrome. This complication has been anticipated before operation by using CT scan, and it was suggested that patient should be given radiotherapy after Y-stent placement as soon as possible.

Initial bronchoscopy evaluation was also necessary before the size of the Y-stent was confirmed. On the one hand, the location, length, and stenosis degree of the involved airway segment should be further checked by bronchoscopy; on the other hand, for some cases, initial bronchoscopy evaluation could help interventional pulmonologists decide whether interventional procedures, such as mechanical debulking, electrosurgery, and laser ablation are needed to relieve stenosis symptoms, thus providing enough time for patients waiting for the customized Y-stent.

This study has a few limitations. First, it was a singlecenter retrospective study. Second, the sample size was small. Third, the data of survival time of patients were incomplete because most patients were referred from other hospitals that were distant from our hospital. When the patients were too sick to tolerate long-distance travel to our hospital, they did not attend further follow-up and were treated in a different local hospital.

In conclusion, the current study described the design and insertion of customized self-expanding bare metal Y-stents and demonstrated the feasibility of their use for maintaining tracheal and main-stem bronchus patency in malignant carinal stenosis. This approach could be used as a bridging method before commencing adjuvant therapy and final palliative therapy for the relief of symptoms.

\section{Acknowledgments}

Funding: This study was supported by the grant from Beijing Natural Science Foundation (7202042).

\section{Footnote}

Reporting Checklist: The authors have completed the STROBE reporting checklist. Available at http://dx.doi. org/10.21037/apm-20-2332
Data Sharing Statement: Available at http://dx.doi. org/10.21037/apm-20-2332

Peer Review File: Available at http://dx.doi.org/10.21037/ apm-20-2332

Conflicts of Interest: All authors have completed the ICMJE uniform disclosure form (available at http://dx.doi. org/10.21037/apm-20-2332). Dr. JZ reports grants from Beijing Natural Science Foundation, during the conduct of the study. The other authors have no conflicts of interest to declare.

Ethical Statement: The authors are accountable for all aspects of the work in ensuring that questions related to the accuracy or integrity of any part of the work are appropriately investigated and resolved. The study was conducted in accordance with the Declaration of Helsinki (as revised in 2013). The study was approved by the Institutional Review Board of Beijing Tian Tan Hospital (approval ID: JS2013-007-02). All patients gave their written informed consent to undergo the stent insertion, and for their data to be used in this study.

Open Access Statement: This is an Open Access article distributed in accordance with the Creative Commons Attribution-NonCommercial-NoDerivs 4.0 International License (CC BY-NC-ND 4.0), which permits the noncommercial replication and distribution of the article with the strict proviso that no changes or edits are made and the original work is properly cited (including links to both the formal publication through the relevant DOI and the license). See: https://creativecommons.org/licenses/by-nc-nd/4.0/.

\section{References}

1. Righini C, Aniwidyaningsih W, Ferretti G, et al. Computed tomography measurements for airway stent insertion in malignant airway obstruction. J Bronchology Interv Pulmonol 2010;17:22-8.

2. Sehgal IS, Dhooria S, Madan K, et al. Placement of tracheobronchial silicone Y-stents: Multicenter experience and systematic review of the literature. Lung India 2017;34:311-7.

3. Dutau H, Toutblanc B, Lamb C, et al. Use of the Dumon Y-stent in the management of malignant disease involving the carina: a retrospective review of 86 patients. Chest 2004;126:951-8. 
4. Ayub A, Al-Ayoubi AM, Bhora FY. Stents for airway strictures: selection and results. J Thorac Dis 2017;9:S116-S21.

5. Ferretti GR, Kocier M, Calaque O, et al. Follow-up after stent insertion in the tracheobronchial tree: role of helical computed tomography in comparison with fiberoptic bronchoscopy. Eur Radiol 2003;13:1172-8.

6. Neville WE, Hamouda F, Andersen J, et al. Replacement of the intrathoracic trachea and both stem bronchi with a molded Silastic prosthesis. J Thorac Cardiovasc Surg 1972;63:569-76.

7. Conforti S, Durkovic S, Rinaldo A, et al. Self-expanding y stent for the treatment of malignant tracheobronchial stenosis. Retrospective study. Arch Bronconeumol 2016;52:e5-e7.

8. Ozdemir C, Sokucu SN, Karasulu L, et al. Placement of self-expandable bifurcated metallic stents without use of fluoroscopic and guidewire guidance to palliate central

Cite this article as: Wang T, Zhang J, Qiu XJ, Wang J, Pei YH, Niu JM. Customized self-expanding bare metal Y stents in the treatment of malignant carinal stenosis: a retrospective analysis. Ann Palliat Med 2021;10(4):4184-4192. doi: 10.21037/apm20-2332 airway lesions. Multidiscip Respir Med 2016;11:15.

9. Gompelmann D, Eberhardt R, Schuhmann M, et al. Selfexpanding $\mathrm{Y}$ stents in the treatment of central airway stenosis: a retrospective analysis. Ther Adv Respir Dis 2013;7:255-63.

10. Qiao Y, Fu YF, Cheng L, et al. Placement of integrated self-expanding Y-shaped airway stent in management of carinal stenosis. Radiol Med 2016;121:744-50.

11. Sesterhenn AM, Wagner HJ, Alfke H, et al. Treatment of benign tracheal stenosis utilizing self-expanding nitinol stents. Cardiovasc Intervent Radiol 2004;27:355-60.

12. Furukawa K, Ishida J, Yamaguchi G, et al. The role of airway stent placement in the management of tracheobronchial stenosis caused by inoperable advanced lung cancer. Surg Today 2010;40:315-20.

13. Lee KS, Lunn W, Feller-Kopman D, et al. Multislice CT evaluation of airway stents. J Thorac Imaging 2005;20:81-8. 